\title{
Climate-Driven Holocene Migration of Forest-Steppe Ecotone in the Tien Mountains
}

\author{
Ying Cheng ${ }^{1}$, Hongyan Liu ${ }^{2}, * \mathbb{0}$, Hongya Wang ${ }^{2}$, Qian Hao ${ }^{3}$, Yue Han ${ }^{2}$, Keqin Duan ${ }^{1}$ \\ and Zhibao Dong ${ }^{1}$ \\ 1 School of Geography and Tourism, Shaanxi Normal University, Xi'an 710119, China; \\ chengyingnature@163.com (Y.C.); kqduan@snnu.edu.cn (K.D.); zbdong@snnu.edu.cn (Z.D.) \\ 2 College of Urban and Environmental Sciences and MOE Laboratory for Earth Surface, Peking University, \\ Beijing 100871, China; why@urban.pku.edu.cn (H.W.); hanyuegeo@foxmail.com (Y.H.) \\ 3 Institute of Surface-Earth System Science, School of Earth System Science, Tianjin University, \\ Tianjin 300072, China; haoqian@tju.edu.cn \\ * Correspondence: lhy@urban.pku.edu.cn
}

Received: 7 September 2020; Accepted: 26 October 2020; Published: 28 October 2020

\begin{abstract}
Climate change poses a considerable threat to the forest-steppe ecotone in arid mountain areas. However, it remains unclear how the forest-steppe ecotone responds to climate change due to the limitation of the traditional pollen assemblages, which greatly limits the understanding of the history of the forest-steppe ecotone. Here, we examined the Tien Mountains, the largest mountain system in the world's arid regions, as a case study to explore the migration of the forest-steppe ecotone using the pollen taxa diversity, by combining modern vegetation surveys, surface pollen and two fossil pollen sequences-in the mid-elevation forest belt (Sayram Lake) and in the low-elevation desert belt (Aibi Lake). We found that the forest-steppe migration followed Holocene climate change. Specifically, the forest belt where Picea schrenkiana Fisch. \& C.A.Mey. dominates has a very low pollen taxa diversity, characterized by high richness and low evenness, which plays a key role in mountainous diversity. By detecting the diversity change of the deposition sites, we found that in coping with the warm and wet middle Holocene, the forest belt expanded and widened as the observed diversities around the two lakes were very low, thus the forest-steppe ecotone moved downward accordingly. During the early and late Holocene, the forest belt and the forest-steppe ecotone moved upward under a warm and dry climate, and downward under a cold and wet climate, as there was a reduced forest belt effect on, or contribution to, the sites, and the observed diversities were high. Moisture loss may pose the greatest threat to the narrow forest-steppe ecotone, considering the climatic niche space and the limited living space for humidity-sensitive taxa. This study highlights that temperature and moisture co-influence the forest belt change, which further determines the position migration of the forest-steppe ecotone.
\end{abstract}

Keywords: pollen analysis; forest belt; forest-steppe ecotone; position migration; moisture change

\section{Introduction}

Arid and semi-arid areas are extremely sensitive to climate change and human activities, and the forest-steppe ecotone in these areas is among the most vulnerable ecosystems in the world [1-3]. Until now, climate change has posed a serious threat to the forest-steppe ecotone in arid and semi-arid areas by causing tree growth decline and tree mortality [2,4,5]. The latest forecasts suggest that the expansion of arid and semi-arid areas will potentially exacerbate regional warming and habitat fragmentation in the future [3,6]. Therefore, there is an urgent need to pay attention to the forest-steppe ecotone in such ecologically fragile areas. 
Pollen taxa concentrates in mountains in arid regions, which are also key areas for ecosystem services. Mountain areas typically have rich and unique pollen taxa [7]. Generally, mountain vegetation belts in arid central Asia have various types, ranging from desert to grassland, forest and alpine meadows as the elevation rises [8]. Among them, mountain forest-steppes, typically situated between the forest and steppe belts, are located at the driest edge of forest distribution vertically $[9,10]$. As such, it is critical to understand the dynamics of the mountain forest-steppe ecotone under climate change in arid regions. Yet, how the change of pollen reflects the migration of the forest-steppe ecotone remains unclear, despite the series of traditional pollen assemblage studies carried out in some hotspots, including the Tibetan Plateau, the Altai Mountains, and the Taibai Mountains [11-13].

Pollen taxa diversity can serve as a comprehensive indicator reflecting the dynamics of the vegetation belts [4]. Whether past climate change increased or decreased pollen taxa diversity has not yet been fully determined, and changes in the pollen taxa diversity potentially include clues for vegetation belt change, especially for the migration of the mountain forest-steppe ecotone. Thus, the Holocene is an ideal period to explore the migration of the forest-steppe ecotone, wherein which climate change was mainly caused by natural variability.

Moreover, it is important to focus on the response modes of mountain vegetation belts to Holocene climate change and to improve the corresponding mechanisms, which are the key to exploring the history of forest-steppe migration. The position of the mountainous vertical vegetation belt is very sensitive to climate change [11,12], because the vertical belt is the epitome of the horizontal belt (about 1/1000). The vertical belt in arid areas is unique, as the upper and lower limits of the forest are affected by temperature and moisture, respectively. Mountain vegetation responds to temperature change by position migration, while it responds to moisture change through changes in species composition $[4,5]$. These two modes are mostly adopted, even though they might not fully explain the mechanism between mountain vegetation belts and changes in temperature and moisture. Studies have indicated that the width of the mountain vegetation belt and climate are not completely in equilibrium [14,15]. As the climate mode can be warm and dry, warm and wet, cold and dry, and cold and wet, both the upper and the lower limits of the forest belt, which are in different climatic conditions, may respond differently [12], which ultimately leads to potential changes in the belt width and position. As such, variations in the width of vegetation belts may also be one of the most typical responses to particular climate change, and may further lead to the change in the forest-steppe ecotone. Therefore, it is of importance to see whether these kinds of response patterns exist in the vegetation belts and can be detected through the change of pollen taxa diversity in arid mountain areas.

The Tien Mountains, the largest mountain system in the world's arid regions, is located in the hinterland of Eurasia, affected by the westerlies [16-18], where the vertical differentiation of vegetation belts is apparent and the typical mountain forest-steppe exists [19]. Due to the complex topographical conditions, limited range size and arid environments, the forest-steppe ecotone in the Tien Mountains appears to be most threatened by climate deterioration. However, few studies have specifically focused on the migration of the forest-steppe ecotone in response to the effect of climate change in the Tien Mountains, despite many studies exploring its climate and vegetation changes at multiple time scales [20-23]. Therefore, there is an urgent need to comprehensively study the response pattern of the forest-steppe ecotone in the Tien Mountains to Holocene climate change based on evidence from both surface pollen and fossil pollen, as pollen can provide a long history of pollen taxa diversity with good temporal continuity [4].

Based on the above description, we aim to explore the following scientific questions: (1) How did the mountainous pollen taxa diversity evolve during the Holocene? (2) How did the pollen taxa diversity reflect the changes in vegetation belts in the Tien Mountains during the Holocene? (3) How did the forest-steppe ecotone migrate in response to the Holocene temperature and moisture change in the Tien Mountains? 


\section{Materials and Methods}

\subsection{Study Area}

The Tien Mountains, the largest mountain system in the world's arid regions, are located in the hinterland of Eurasia, influenced by westerlies (Figure 1a,b) [16]. The annual mean precipitation on the northern slopes changes from $175 \mathrm{~mm}$ in the desert zone to $465 \mathrm{~mm}$ in the mid-altitude zone [24].
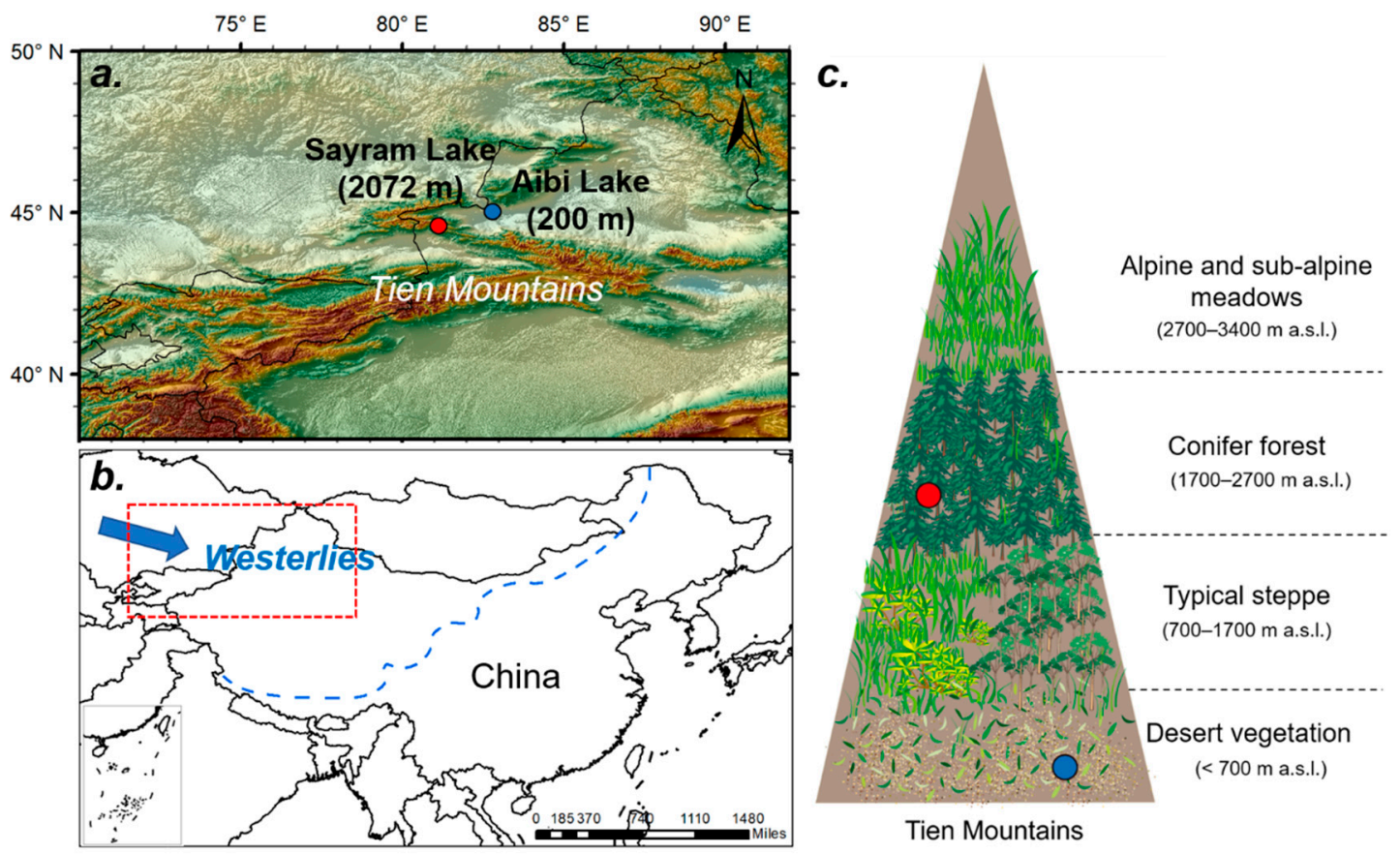

Figure 1. The location of the Tien Mountains in the hinterland of Eurasia, influenced by westerly winds. (a) Digital elevation model image of the study area. The red solid dot represents the location of Sayram Lake, while the blue one represents the location of Aibi Lake. (b) The red dotted area represents the range of subgraph. The blue dotted line represents the modern limit of the East Asian summer monsoon, which also illustrates the horizontal limit of the westerlies effect. (c) Vegetation belts on the northern slope of the Tien Mountains.

The Tien Mountains have the most typical and complete vertical natural belt spectrum for temperate arid areas around the world, reflecting the distribution characteristics and changes in the mountain pollen taxa diversity and ecological processes. The northern slope of the Tien Mountains can be divided into the following vegetation belts [14] (Figure 1c): sparse and low cushion vegetation is distributed in high mountain belts above $3400 \mathrm{~m}$ a.s.l.; alpine and subalpine meadows dominate from 2700 to $3400 \mathrm{~m}$ a.s.l.; conifer forest is distributed on the middle elevations from 1700 to $2700 \mathrm{~m}$ a.s.l.; typical steppe dominates from 700 to $1700 \mathrm{~m}$ a.s.l., represented by steppe on the sunny slope and patchy forest on the shady slope; desert vegetation is distributed below $700 \mathrm{~m}$ a.s.l. Notably, the forest-steppe ecotone, also known as the transition zone between the forest belt and the steppe belt, is currently situated around $1700 \mathrm{~m}$ a.s.l. on the northern slope of the Tien Mountains [14].

\subsection{Modern Vegetation Survey}

To investigate the changes in the richness of modern plant species along the elevational gradient, typical plots representing the characteristic vegetation composition in each vegetation belt were selected, based on the natural geographical pattern of the Tien Mountains [14]. In the mountainous area, with an elevation from 700 to $1700 \mathrm{~m}$ a.s.l., plots were sampled every $100 \mathrm{~m}$ along the elevational gradient. Due to a flat terrain in the oasis and the downstream desert area, plots were sampled every 
$50 \mathrm{~km}$ in the horizontal direction. Finally, 40 valid plots were surveyed. During the sample survey, the forest plot area was $10 \mathrm{~m} \times 10 \mathrm{~m}$, and the grassland or meadow community area was $2 \mathrm{~m} \times 2 \mathrm{~m}$. Then the detailed information about vegetation habitat conditions, species composition, coverage and height were recorded.

\subsection{Surface Pollen}

Surface soil samples were collected every $100 \mathrm{~m}$ in the range of 200 to $3500 \mathrm{~m}$ a.s.l. on the northern slope of the Tien Mountains, and 34 samples were obtained to investigate the changes in surface pollen composition and evenness in each vegetation belt [14]. Pollen was extracted by treating with $\mathrm{HCl}$ $(10 \%)$ and $\mathrm{NaOH}(10 \%)$, then sieved through $180 \mu \mathrm{m}$ and $10 \mu \mathrm{m}$ sieves, and floated with heavy liquid $(\mathrm{KI}+\mathrm{HI}+\mathrm{Zn})$ using standard techniques [25]. Each sample was counted to contain at least 250 pollen grains under an optical microscope at $400 \times$ magnification.

\subsection{Fossil Pollen}

We selected two typical fossil pollen sites with high resolution on the northern slope of the Tien Mountains to explore the evolution of pollen taxa diversity. We digitized all pollen taxa using GetData Graph Digitizer v2.25 software [26] and then used them as analytical paleo data. Considering the location representativeness, age, temporal resolution and pollen identification of fossil pollen cores, the following two sites can meet our analysis needs.

The first sediment core, named SLMH-2009 $\left(44^{\circ} 35^{\prime} \mathrm{N}, 81^{\circ} 09^{\prime} \mathrm{E}\right)$, was from Sayram Lake, with an elevation of $2072 \mathrm{~m}$ (Figure 1a,b) [22], and was located in the middle-low part of the modern conifer forest belt. This core was dated back to the Late Glacial to early Holocene transition, with $11 \mathrm{AMS}^{14} \mathrm{C}$ dates, and had a temporal resolution of less than 100 years for each pollen sample. The authors analyzed 150 fossil pollen samples in total, with a minimum of 400 pollen grains identified for each sample.

The second sediment core, named A-01, was from Aibi Lake $\left(44^{\circ} 54^{\prime}-45^{\circ} 08^{\prime} \mathrm{N}, 82^{\circ} 35^{\prime}-83^{\circ} 10^{\prime} \mathrm{E}\right)$ (Figure 1a,b) [23], located in the desert vegetation belt at $200 \mathrm{~m}$ a.s.l. This core was dated back to the Late Glacial to early Holocene transition with eight $\mathrm{AMS}^{14} \mathrm{C}$ dates and had a temporal resolution of less than 150 years for each pollen sample. The authors analyzed 195 fossil pollen samples in total, with a minimum of 350 pollen grains identified for each sample.

\subsection{Pollen Taxa Diversity Index}

We chose the Shannon-Wiener index and Simpson index to calculate the pollen taxa diversity, as these two indices include the heterogeneity of the measured plant community. They consider both the richness and evenness of the species in the community. Specifically, the Shannon-Wiener diversity index was used to estimate the level of pollen taxa diversity in the modern ecosystem and in the Holocene, which is a comprehensive index reflecting richness and evenness. Its formula is as follows [27].

$$
\mathrm{H}=-\sum_{i=1}^{\mathrm{r}} P i \ln P i
$$

$P i=n i / N$, indicating the relative richness of species.

ni represents the number of individuals of each pollen taxon.

$N$ represents the total number of individuals of all pollen taxa in the community.

It should be noted that communities with low richness and high evenness, and communities with high richness and low evenness, have low diversity indices. 
The Simpson diversity index was also used to present the pollen taxa diversity. Unlike the Shannon-Wiener index, the Simpson index measures the probability that two random entities from the pollen group represent different pollen taxa, which can be quantified by the following equation [28].

$$
\mathrm{D}=1-\sum_{i=1}^{\mathrm{N}} P_{i}^{2}
$$

$P i=n i / N$, indicating the relative richness of species.

$n i$ represents the number of individuals of each pollen taxon.

$N$ represents the total number of individuals of all pollen taxa in the community.

\subsection{Climate Data}

Holocene temperature change was acquired from the integrated results of paleoclimate records for $30-90^{\circ} \mathrm{N}[29,30]$, and Holocene moisture change was derived from integrated results of paleoclimate records in arid central Asia [16].

\section{Results}

\subsection{Modern Plant Species Richness Changes along the Elevational Gradient}

We observed an increasing richness of modern plant species from low-elevation areas to mid-elevation mountainous areas (Figure 2). Regarding the oasis and the downstream desert area from 200 to $700 \mathrm{~m}$ a.s.l., plant species richness was limited, ranging from 4 to 17 (Figure 2). The range of 200 to $400 \mathrm{~m}$ a.s.l. belongs to the oasis area, with a relatively high number of species; therefore, the observed plant species greatly fluctuated (Figure 2). From $700 \mathrm{~m}$ a.s.l. to the middle elevation, plant species richness showed an increasing trend, with a peak occurring in the forest belt at $1700 \mathrm{~m}$ a.s.l. (Figure 2). According to our field survey, the wet-preferring species Picea schrenkiana Fisch. \& C.A.Mey. was dominating the forest belt, and the richness of the forest belt was mainly caused by the species richness of the understory, which can reach nearly 40 species (Figure 2).

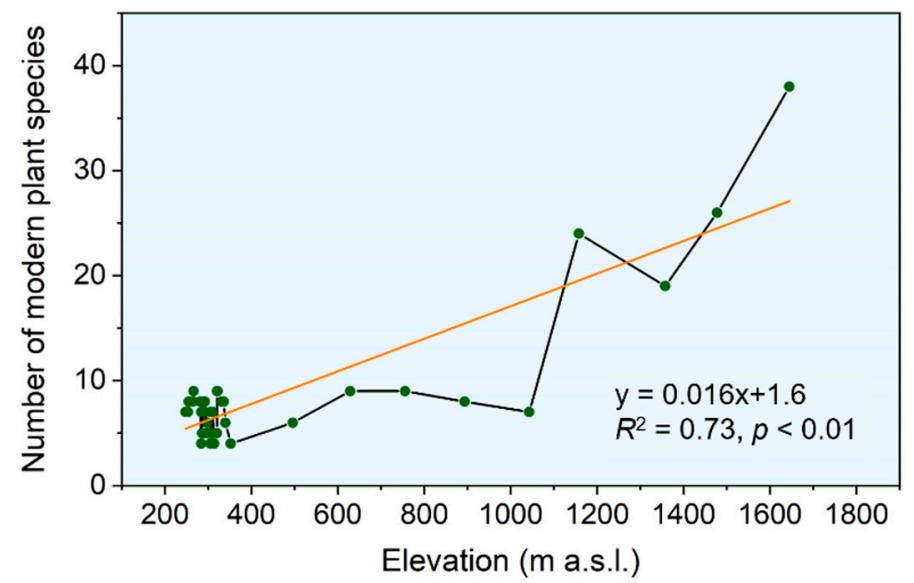

Figure 2. The richness of modern plant species along the elevational gradient. The orange line represents the linear regression line.

\subsection{Surface Pollen Composition}

The surface pollen taxa within the range of 250-3500 $\mathrm{m}$ on the northern slope of the Tien Mountains were analyzed according to their richness changes along the elevational gradient (Figure 3). Salix, Ephedra, Caryophyllaceae, Asteraceae, Thalictrum, Ranunculaceae, and Rosaceae peaked in the range of 3500-2700 m. Picea, Poaceae, and Ranunculaceae reached a peak in the range of 2700-1700 m. 
Betula, Artemisia, Salix, Tamarix, Ephedra, Thalictrum, and Rosaceae peaked between 1700 and $700 \mathrm{~m}$. Ulmus, Amaranthaceae, Nitraria, and Tamarix reached a peak below $700 \mathrm{~m}$.

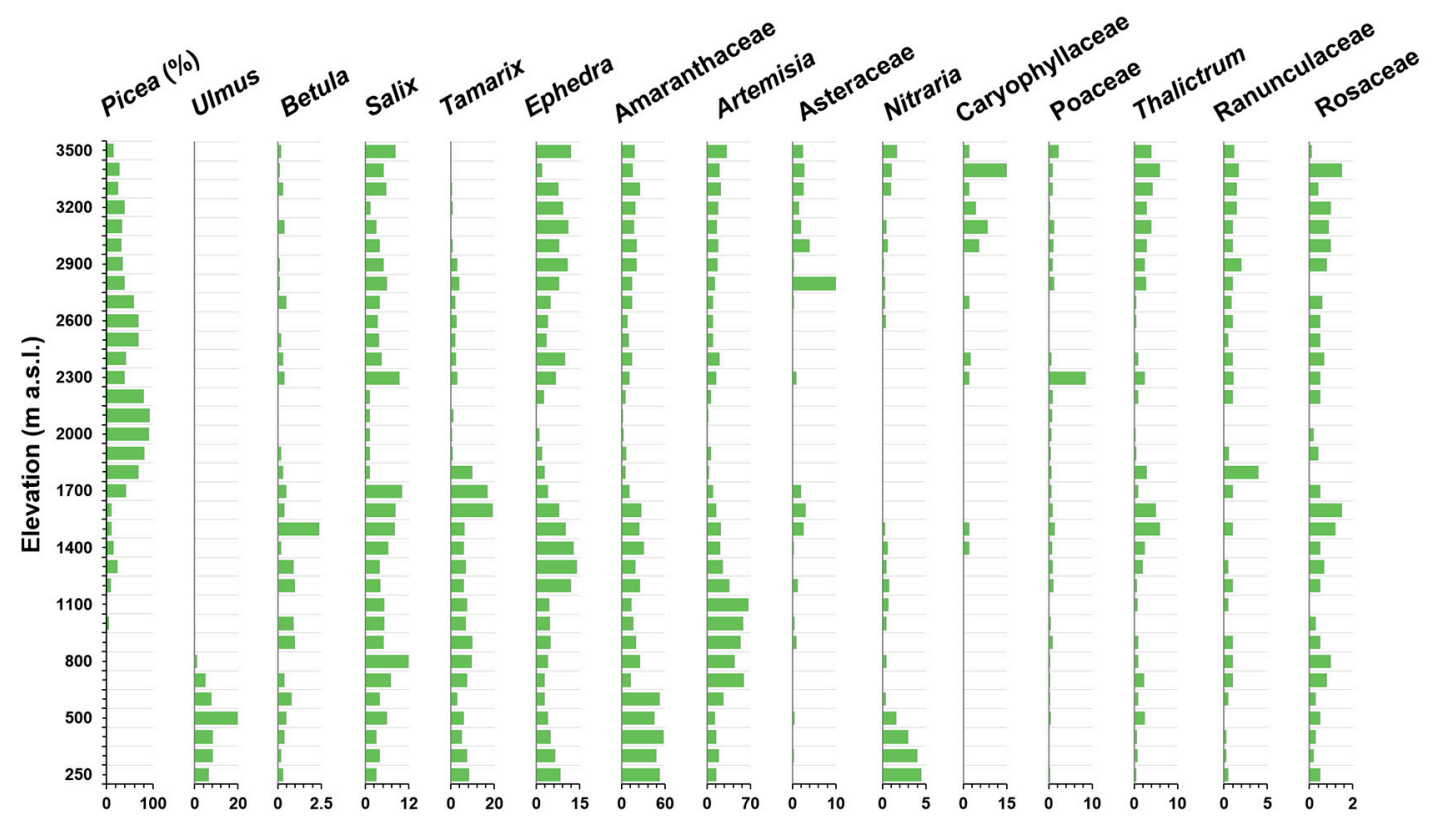

Figure 3. The richness of surface pollen taxa along the elevational gradient.

These taxa were further divided into the following four vegetation belts (Table 1). Alpine and sub-alpine meadows mainly included Salix, Ephedra, Caryophyllaceae, Asteraceae, Thalictrum, Ranunculaceae, and Rosaceae. These taxa can endure cold climates in the alpine zone. Conifer forest mainly included Picea, Poaceae and Ranunculaceae, where Picea schrenkiana was the dominant species favored by the wet climatic conditions. The typical steppe mainly contained Betula, Artemisia, Salix, Tamarix, Ephedra, Thalictrum, and Rosaceae. Betula fruticosa Pallas was located in the desert belt in front of the mountain, and is categorized as azonal vegetation. Desert vegetation contained Ulmus, Amaranthaceae, Nitraria and Tamarix. Ulmus pumila L. was distributed in the low-elevation river valleys, also belonging to the azonal vegetation classification. Amaranthaceae, Nitraria, and Tamarix are typically drought-tolerant species. Based on our division criteria, the richness of fossil pollen in the studied sedimentary site probably originated from different vegetation belts, which is soon discussed.

Table 1. Lists of main surface pollen taxa assigned to different vegetation belts along the northern slope of the Tien Mountains.

\begin{tabular}{|c|c|c|c|}
\hline $\begin{array}{l}\text { Alpine and Sub-Alpine Meadows } \\
\quad 3500-2700 \mathrm{~m} \text { a.s.l. }\end{array}$ & $\begin{array}{c}\text { Conifer Forest } \\
2700-1700 \text { m a.s.1. }\end{array}$ & $\begin{array}{l}\text { Typical Steppe } \\
1700-700 \mathrm{~m} \text { a.s.l. }\end{array}$ & $\begin{array}{l}\text { Desert Vegetation } \\
\text { Below } 700 \mathrm{~m} \text { a.s.1. }\end{array}$ \\
\hline $\begin{array}{c}\text { Salix } \\
\text { Ephedra } \\
\text { Caryophyllaceae } \\
\text { Asteraceae } \\
\text { Thalictrum } \\
\text { Ranunculaceae } \\
\text { Rosaceae }\end{array}$ & $\begin{array}{c}\text { Picea } \\
\text { Poaceae } \\
\text { Ranunculaceae }\end{array}$ & $\begin{array}{c}\text { Betula } \\
\text { Artemisia } \\
\text { Salix } \\
\text { Tamarix } \\
\text { Ephedra } \\
\text { Thalictrum } \\
\text { Rosaceae }\end{array}$ & $\begin{array}{c}\text { Ulmus } \\
\text { Amaranthaceae } \\
\text { Nitraria } \\
\text { Tamarix }\end{array}$ \\
\hline
\end{tabular}

Moreover, in the modern ecosystem, the Shannon-Wiener index and the Simpson index consistently indicated the lowest pollen taxa diversity in the forest belt, while the highest pollen taxa diversity was in the alpine and sub-alpine meadows belt, followed by the typical steppe belt, and the desert vegetation belt (Table 2). According to the result of the Shannon-Wiener index, in the upper (2800-2600 m) and lower (1800-1600 $\mathrm{m}$ ) boundaries and the center of the forest belt $(2400-2100 \mathrm{~m})$, the pollen taxa 
diversities were 1.49, 1.65, and 1.21, respectively (Table 2). According to the result of the Simpson index, in the upper (2800-2600 m) and lower (1800-1600 m) boundaries and the center of the forest belt (2400-2100 m), the pollen taxa diversities were 0.63, 0.70, and 0.50, respectively (Table 2). Based on the results of the surface pollen analyses, we inferred that the pollen taxa diversity of the forest belt was generally low in the Tien Mountains, which was related to the very low pollen evenness due to the absolute dominance of Picea pollen in the forest belt (varying from 39\% to 93\%, with a mean of $67 \%$ ) (Figures 2 and 3). Therefore, we inferred that the forest belt with very low pollen taxa diversity might affect the changes in pollen taxa diversity observed by the deposition sites during the Holocene, even though the forest belt had a larger plant species number than the belts of the typical steppe and desert vegetation (Figure 3).

Table 2. Vegetation belt and the pollen taxa diversity in the modern ecosystem.

\begin{tabular}{cccc}
\hline Vegetation Belt & $\begin{array}{c}\text { Altitude } \\
\text { (m a.s.1.) }\end{array}$ & $\begin{array}{c}\text { Pollen Taxa Diversity Indicated by } \\
\text { the Shannon-Wiener Index }\end{array}$ & $\begin{array}{c}\text { Pollen Taxa Diversity Indicated by } \\
\text { the Simpson Index }\end{array}$ \\
\hline Alpine and sub-alpine meadows & $3500-2700$ & 1.84 & 0.78 \\
Transition zone (forest upper boundary) & $2800-2600$ & 1.49 & 0.63 \\
Conifer forest & $2700-1700$ & 1.16 & 0.49 \\
The center of the forest belt & $2400-2100$ & 1.21 & 0.50 \\
Transition zone (forest lower boundary) & $1800-1600$ & 1.65 & 0.70 \\
Typical steppe & $1700-700$ & 1.68 & 0.72 \\
Desert vegetation & Below 700 & 1.52 & 0.67 \\
\hline
\end{tabular}

\subsection{Pollen Taxa Diversity Change around Sayram Lake during the Holocene}

During the Holocene, belts of alpine and sub-alpine meadows, conifer forest and desert vegetation contributed to the pollen taxa diversity around Sayram Lake, while the belt of the typical steppe did not contribute, according to the regression relationships between pollen taxa diversity indicated by the Shannon-Wiener index and pollen richness from different vegetation belts (Figure 4). The linear regression showed that the conifer forest belt contributed the most to the pollen taxa diversity around Sayram Lake through the Holocene $\left(R^{2}=0.40, p<0.01\right)$, while contributions from the belts of alpine and sub-alpine meadows and desert vegetation were relatively small $\left(R^{2}=0.25, p<0.01\right.$ and $R^{2}=0.37$, $p<0.01$, respectively) (Figure 4). This further suggests that pollen taxa diversity around Sayram Lake can reflect the forest belt change during the Holocene.
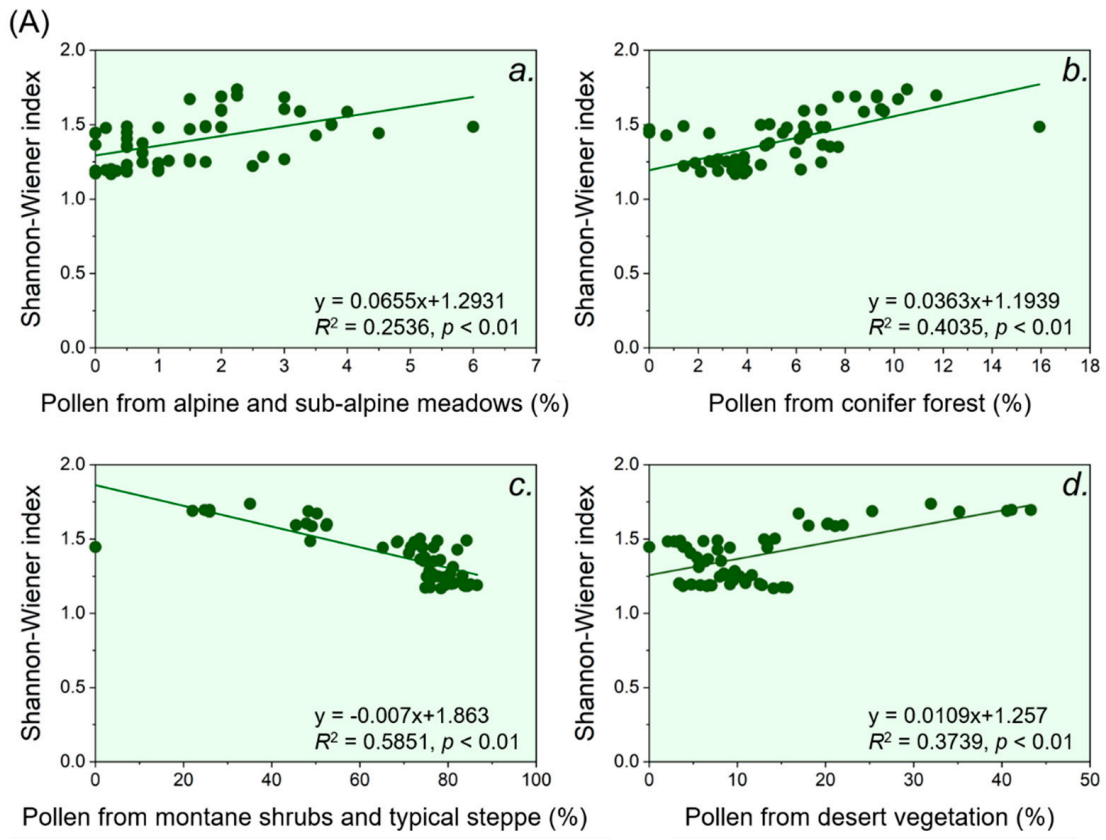

Figure 4. Cont. 
(B)
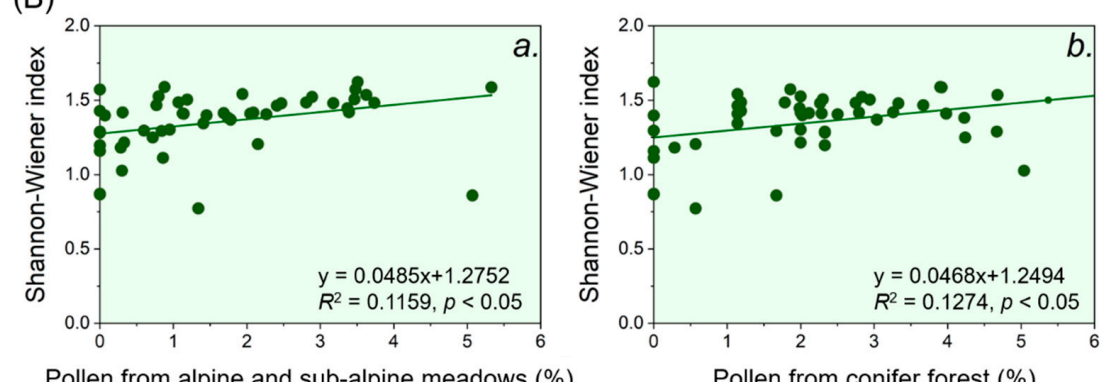

Pollen from alpine and sub-alpine meadows (\%)

Pollen from conifer forest (\%)
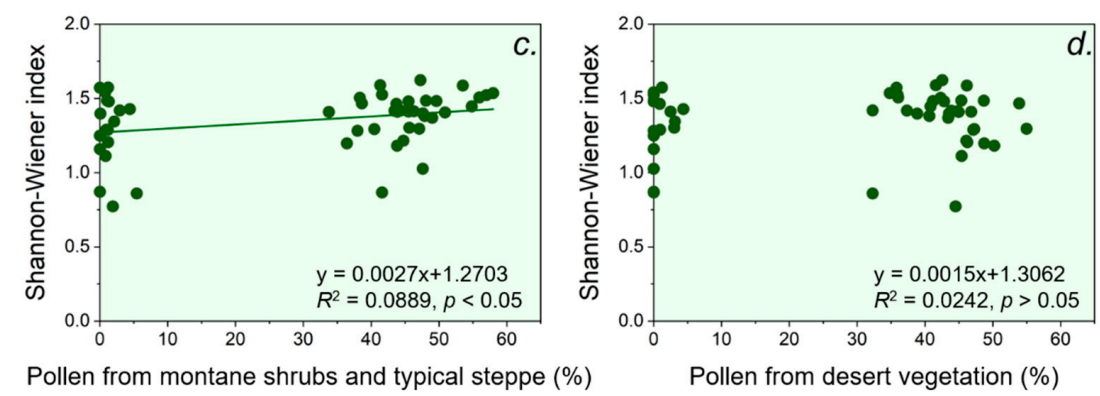

Figure 4. Linear relationships between the observed pollen percentage from different vegetation belts and the Shannon-Wiener index. Notably, the horizontal axis represents the sum of the percentage of pollen taxa derived from different vegetation belts (from a to d) observed in the sedimentary sites (specific taxa contained in each vegetation belt are listed in Table 1). Panel (A) represents Sayram Lake, and panel (B) represents Aibi Lake.

During the warm and dry periods of the early Holocene, from 12,000 to 8000 years before present (yr BP) (Figure 5a,b), the conifer forest belt moved up, and the belts of alpine and sub-alpine meadows and typical steppe moved up as well (Figure 6a), because the observed pollen taxa diversity indicated by the Shannon-Wiener index around Sayram Lake was very high, reaching a mean of 1.56 (Figure 5c), which was close to the diversity index (1.65) of the lower boundary of the modern forest belt (Table 2). Moreover, the observed pollen taxa diversity indicated by the Simpson index around Sayram Lake was also very high, reaching a mean of 0.69 (Figure $5 \mathrm{~d}$ ), which was close to the diversity index $(0.70)$ of the lower boundary of the modern forest belt (Table 2). Therefore, we infer that Sayram Lake was probably at the lower boundary of the conifer forest during the early Holocene, thus the forest-steppe ecotone moved upward accordingly, and was close to Sayram Lake. 


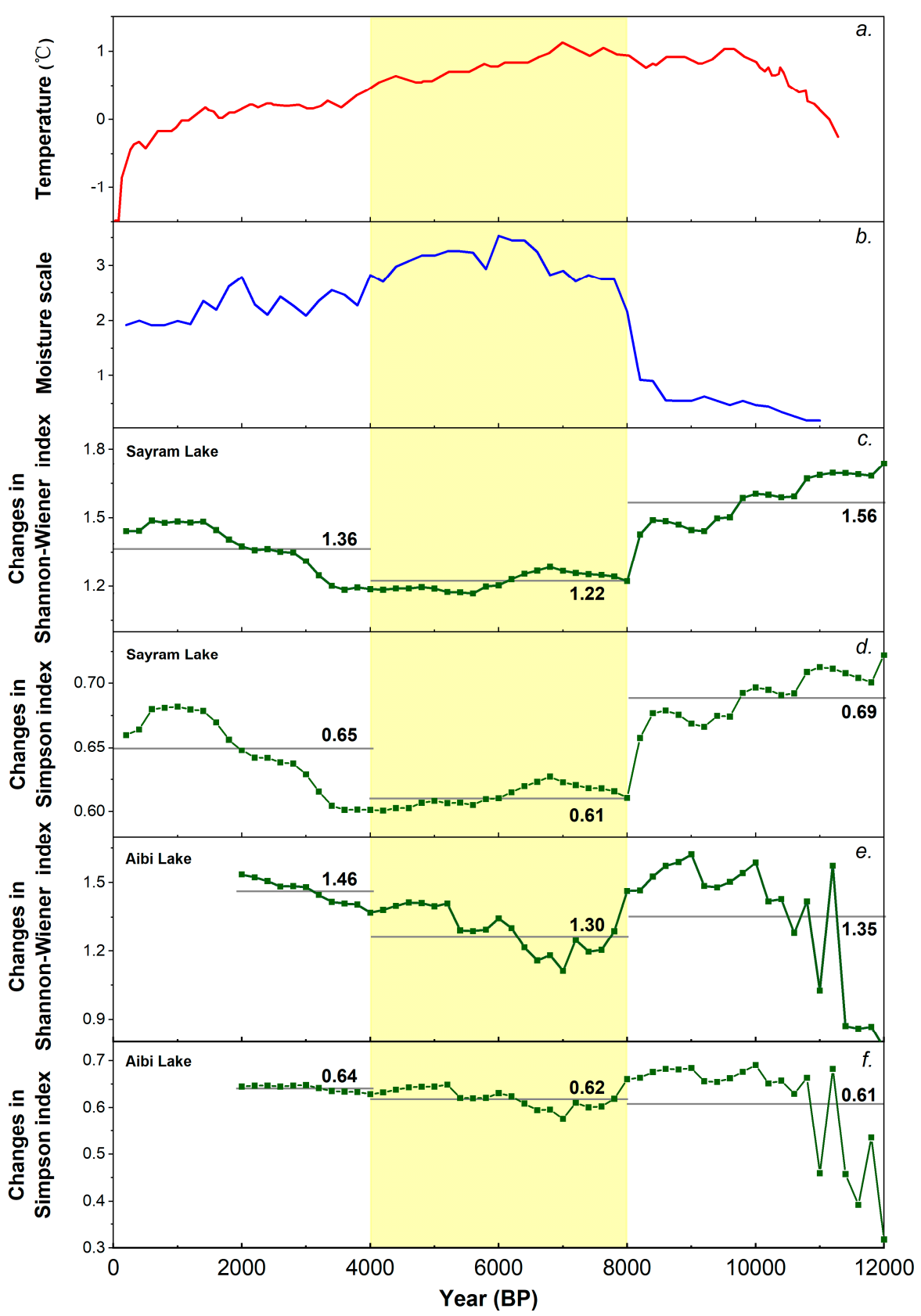

Figure 5. Changes in pollen taxa diversity in the Tien Mountains and the Holocene climate. (a) Holocene temperature change for 30-90 $\mathrm{N}$ [29,30]. (b) Holocene moisture changes in arid central Asia [16]. Gray lines represent mean levels of pollen taxa diversity index during different periods around Sayram Lake and Aibi Lake (c-f). The yellow area represents the middle Holocene with low pollen taxa diversity. 


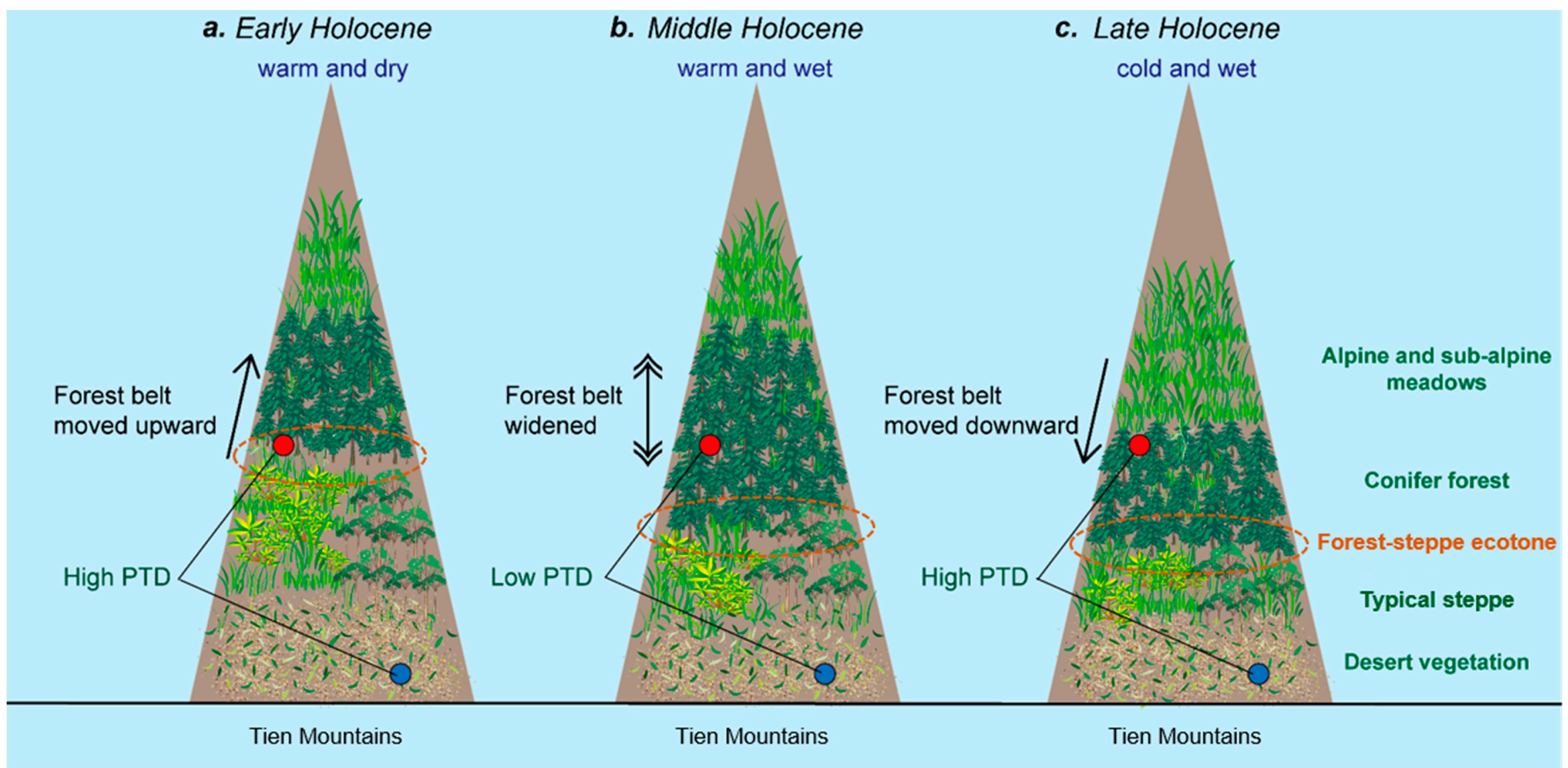

Figure 6. Schematic diagram presenting changes in pollen taxa diversity (PTD) and the migration of the forest-steppe ecotone under the Holocene's changing climate $(\mathbf{a}-\mathbf{c})$. In the belt of the typical steppe, the steppe is mainly distributed on the sunny slope, while the forest is distributed on the shady slope. The red dot represents the location of Sayram Lake, while the blue dot indicates the location of Aibi Lake. The orange ellipse indicates the possible range of the forest-steppe ecotone. 
During the middle Holocene, from 8000 to 4000 yr BP (Figure 5a,b), when the climate was warm and wet compared to the last stage, the conifer forest belt expanded and dominated, while the belts of alpine and sub-alpine meadows and the typical steppe were conversely compressed (Figure 6b), as the observed pollen taxa diversity indicated by the Shannon-Wiener index around Sayram Lake was very low, reaching a mean of 1.22 (Figure 5c), which was close to the diversity index (1.21) in the center of the modern forest belt (Table 2). In addition, the observed pollen taxa diversity indicated by the Simpson index around Sayram Lake was also very low, reaching a mean of 0.51 (Figure $5 \mathrm{~d}$ ), which was close to the diversity index (0.50) in the center of the modern forest belt (Table 2). Therefore, Sayram Lake was probably in the center of the forest belt during the middle Holocene, and the forest-steppe ecotone probably moved downward accordingly (Figure 6b).

As the late Holocene climate became cold and wet from 4000 yr BP onwards (Figure 5a,b), the conifer forest belt moved downward, and the belts of alpine and sub-alpine meadows and the typical steppe moved down as well (Figure 6c), because the observed pollen taxa diversity indicated by the Shannon-Wiener index around Sayram Lake was relatively high, reaching a mean of 1.36 (Figure 5c), which was close to the diversity index (1.49) of the upper boundary of the modern forest belt (Table 2). In addition, the observed pollen taxa diversity indicated by the Simpson index around Sayram Lake was also relatively high, reaching a mean of 0.65 (Figure $5 \mathrm{~d}$ ), which was close to the diversity index (0.63) of the upper boundary of the modern forest belt (Table 2). Therefore, we infer that Sayram Lake was probably at the upper boundary of the conifer forest during the late Holocene, and the forest-steppe ecotone moved further down and away from Sayram Lake (Figure 6c).

\subsection{Pollen Taxa Diversity Change Around Aibi Lake during the Holocene}

During the Holocene, the belts of alpine and sub-alpine meadows, conifer forest and typical steppe all contributed to the pollen taxa diversity around Aibi Lake, as the relationships between pollen taxa diversity indicated by the Shannon-Wiener index and the pollen richness from these belts were all positive (Figure 4). Notably, the belt of the conifer forest contributed the most to the pollen taxa diversity around Aibi Lake, according to the result of our linear regression $\left(R^{2}=0.13, p<0.05\right)$, followed by the alpine and sub-alpine meadows belts $\left(R^{2}=0.12, p<0.05\right)$ and the typical steppe belt $\left(R^{2}=0.09, p<0.05\right)$ (Figure 4$)$. This further suggests that pollen taxa diversity around Aibi Lake can reflect the forest belt change during the Holocene.

During the warm and dry periods of the early Holocene from 12,000 to $8000 \mathrm{yr}$ BP (Figure 5a,b), the conifer forest belt moved upward (Figure 6a), and the forest belt contributed less to the low-elevation deposition site of Aibi Lake and no longer dominated its diversity change, as the observed pollen taxa diversity was high, with a value of 1.35 indicated by the Shannon-Wiener index (Figure 5e). As such, we infer that the forest-steppe ecotone moved upward accordingly.

During the middle Holocene from 8000 to $4000 \mathrm{yr}$ BP, when the climate was warm and wet compared to the last stage (Figure $5 a, b)$, the conifer forest belt expanded and dominated (Figure 6b), and the forest belt heavily affected the low-elevation deposition site of Aibi Lake, as the observed pollen taxa diversity was low, with a value of 1.30 indicated by the Shannon-Wiener index, and a value of 0.62 indicated by the Simpson index (Figure 5e,f). Therefore, we infer that the forest-steppe ecotone moved downward accordingly.

As the late Holocene climate became cold and wet from 4000 yr BP onwards (Figure 5a,b), the conifer forest belt moved downward, but its area became smaller with low contribution compared to the last stage, because the observed pollen taxa diversity was high, with a value of 1.46 indicated by the Shannon-Wiener index, and a value of 0.64 indicated by the Simpson index (Figure 5e,f). Therefore, we infer that the forest-steppe ecotone moved further down accordingly. 


\subsection{Comparison between the Two Lakes}

The regression relationships between the pollen taxa diversity calculated using the Shannon-Wiener index and the pollen richness from different vegetation belts showed that pollen taxa diversities around Sayram Lake and Aibi Lake can reflect the forest belt change during the Holocene. When the forest belt expanded, Picea pollen dominated, leading to a decrease in the degree of species evenness in the conifer forest belt, because the pollen taxa diversity observed at the two sites was very low.

In general, the pollen taxa diversities around Sayram Lake and Aibi Lake had the same pattern of change in response to the Holocene climate change (Figure 5). In the process of coping with the warm and dry climate during the early Holocene, the forest belt moved upward (Figures 5 and 6a), as Sayram Lake had a high observed pollen taxa diversity (Figures 5 and 6a). In addition, Aibi Lake's pollen taxa diversity was also high, with less contribution from the upward forest belt (Figures 5 and $6 a$ ). Therefore, the forest-steppe ecotone moved upward accordingly during the early Holocene. In response to the warm and wet climate during the middle Holocene, the forest belt widened (Figure 6b), as Sayram Lake had very low observed pollen taxa diversity (Figures 5 and 6b). In addition, the Picea schrenkiana-dominated forest belt heavily influenced the low-elevation deposition site of Aibi Lake, as the observed pollen taxa diversity was low (Figures 5 and $6 \mathrm{~b}$ ). Hence the forest-steppe ecotone moved downward accordingly during the middle Holocene. In response to the cold and wet climate during the late Holocene, the conifer forest belt moved further downward (Figure 6c), as Sayram Lake had a high observed pollen taxa diversity (Figures 5 and $6 c$ ). In addition, Aibi Lake had a high observed pollen taxa diversity, with less contribution from the reduced forest belt (Figures 5 and $6 \mathrm{c}$ ). Thus, the forest-steppe ecotone moved further down accordingly during the late Holocene.

\section{Discussion}

Our results show that changes in the forest-steppe ecotone followed the Holocene climate change in the Tien Mountains. As the degree of temperature and moisture changed, the forest belt changed, which further determines the position migration of the forest-steppe ecotone, as supported by the changes in the pollen taxa diversity observed by the deposition sites in the Tien Mountains (Figures 5 and 6). Under the co-influence of solar insolation and westerlies, climate change exhibits a unique pattern in arid central Asia, characterized by warm and dry climates during the early Holocene, warm and wet climates during the middle Holocene, and moderately cold and wet climates during the late Holocene (Figure 5a,b) [16,18,19,29,31]. The forest belt with Picea pollen dominance expanded and widened during the middle Holocene, leading to a decrease in the degree of species evenness of the conifer forest belt, as the observed pollen taxa diversity around the two lakes was very low. Specifically, on the northern slope of the Tien Mountains, the mid-elevation humid environment favors the existence of Picea schrenkiana, which largely affects mountainous diversity, as supported by our surface pollen results (Figure 3; Table 2). Indeed, this kind of mid-elevation forest distribution is popular in arid and semi-arid mountainous areas in China, which has gained wide attention [5,12,19,32]. Moreover, both the forest belt and the forest-steppe ecotone moved upward during the early Holocene and downward during the late Holocene, leading to a reduced forest belt influence on the sites, as the observed pollen taxa diversities were high (Figure 3; Table 2).

Indeed, Holocene temperature and moisture changes in arid central Asia have affected the vertical migration of vegetation belts and their species composition in mountainous areas [18,19]. The upper limit of the forest belt is controlled by temperature, while the lower boundary is limited by moisture. When the climate is warm and dry, the forest belt moves up along the elevation to acquire more moisture, and vice versa $[11,33]$. The species composition changes from wet-preferring to drought-tolerant species when climate drying exceeds its physiological limits [5]. Besides this, we found that the forest belt responded to the warm and wet climate through the width of the forest belt, which further made the forest-steppe ecotone move downward accordingly. This corresponding mode was also found in the Holocene change of vegetation belts in the Manas River drainage on the northern slope of the Tien Mountains [14]. Therefore, we emphasize that the migration of the forest-steppe ecotone responded 
to the Holocene climate change as the forest belt changed, as supported by the change in pollen taxa diversity at the deposition sites.

Although the pollen taxa diversity in arid mountain areas can reflect vegetation belt change (Figures 5 and 6), does a narrowed forest belt lead to a decline in mountain pollen taxa diversity, and further affect the estimation of the forest-steppe ecotone migration? If the width or area of the forest belt becomes narrower, then the pollen taxa diversity observed at the deposition sites is considered to decline. However, we emphasize that if only the width of the forest belt is reduced, while forest species richness and evenness do not change, then the pollen taxa diversity may not necessarily decline. Furthermore, it is worth noting that some taxa in the forest-steppe ecotone may disappear when climate drying exceeds its threshold in arid mountainous areas. Moisture loss may pose the greatest threat to a relatively narrow forest-steppe ecotone, considering the climatic niche space of humidity-sensitive taxa and their limited living space. For example, as one of the diversity hot spots in the world, the narrow vegetation belts of the eastern Andes show great vulnerability to climate warming, as the expected rates of climate change may move the narrowly distributed taxa out of the climate niche space in hundreds of years [34]. More seriously, as global warming intensifies, regional aridity is expected to become more severe and last longer than in the present dry climate in arid regions [3]. Therefore, it seems that future climate warming with the associated lower moisture will probably cause unexpected threats to the taxa with narrow elevational distributions, especially for the taxa in the forest-steppe ecotone in the Tien Mountains. We thus propose that for the protection and maintenance of the current forest-steppe ecotone in mountainous areas, much attention should be paid to humidity-sensitive taxa under the drying climate.

Besides this, pollen taxa diversity may serve as an important proxy for reflecting the migration of the forest-steppe ecotone [4]. However, there are uncertainties, mainly due to the following aspects. Firstly, the limitation of pollen indicators-potential uncertainties come from differences in the pollen productivity and dispersal ability among various species [4,35-37], which may not present a one-to-one dynamic of vegetation belts and richness of fossil pollen. Secondly, the impact of vegetation structure-for wind-transported pollens, their ability to spread in the woodland is much worse than that in open land. This not only affects the amount of pollen that can be observed at the deposition site, but also affects our ability to recover vegetation using pollen data [38]. Thirdly, different pollen types have different representativeness - if a community with the same species composition has different coverage, the yield of pollen will also be different. When the number of statistical grains is constant, the low-representative species may not be counted, which will affect the estimation of pollen taxa diversity and in future will affect the estimation of the migration of the forest-steppe ecotone [38]. Because this study is mainly based on the Shannon-Wiener index and the Simpson index for calculating the pollen taxa diversity, which takes into account both richness and uniformity, taxa with very low pollen numbers or percentages have little effect on the results.

\section{Conclusions}

We found that the forest-steppe migration generally followed Holocene climate change in the Tien Mountains. Specifically, the forest belt where Picea schrenkiana dominates has a very low pollen taxa diversity, characterized by high richness and low evenness, which plays a key role in the mountainous diversity. By detecting the diversity change of the deposition sites, we found that in the process of coping with warm and dry climate during the early Holocene from 12,000 to $8000 \mathrm{yr}$ BP, the forest belt moved upward, causing a reduced forest belt influence on, or contribution to, the low-elevation deposition sites, as the observed diversities around the two lakes were high. In this case, the forest-steppe ecotone moved upward accordingly. During the warm and wet middle Holocene from 8000 to $4000 \mathrm{yr}$ BP, the forest belt with low taxa evenness expanded and widened, as the observed diversities around the two lakes were very low. As such, the forest-steppe ecotone moved downward accordingly. As the late Holocene became cold and wet from $4000 \mathrm{yr}$ BP onwards, the forest belt moved downward, resulting in a reduced forest belt influence on or contribution to the sites, leading to the high diversities observed. 
Thus the forest-steppe ecotone moved further down. Moisture loss may pose the greatest threat to the narrow forest-steppe ecotone, considering the climatic niche space and the limited living space for humidity-sensitive taxa. This study highlights that temperature and moisture co-influence the forest belt change, which further determines the migration of the forest-steppe ecotone.

Author Contributions: H.L. and Y.C. proposed the idea and designed the study. Y.C. analyzed the data and wrote the first draft. Y.C., H.L., H.W., Q.H., Y.H., K.D. and Z.D. discussed the results and contributed to improving the manuscript. All authors have read and agreed to the published version of the manuscript.

Funding: This research was funded by the National Natural Science Foundation of China, Grant Number 41790422, 41901092. It was also funded by the Fundamental Research Funds for the Central Universities of China, Grant Number GK202003069.

Conflicts of Interest: The authors declare no conflict of interest.

\section{References}

1. Bailey, R.M. Spatial and temporal signatures of fragility and threshold proximity in modelled semi-arid vegetation. Proc. R. Soc. B 2010, 278, 1064-1071. [CrossRef]

2. Liu, H.Y.; Park Williams, A.; Allen, C.D.; Guo, D.; Wu, X.; Anenkhonov, O.A.; Badmaeva, N.K.; Liang, E.; Sandanov, D.V.; Yin, Y.; et al. Rapid warming accelerates tree growth decline in semi-arid forests of inner Asia. Glob. Chang. Biol. 2013, 19, 2500-2510. [CrossRef]

3. Huang, J.; Yu, H.; Guan, X.; Wang, G.; Guo, R. Accelerated dryland expansion under climate change. Nat. Clim. Chang. 2016, 6, 166-171. [CrossRef]

4. Weng, C.; Hooghiemstra, H.; Duivenvoorden, J.F. Response of pollen diversity to the climate-driven altitudinal shift of vegetation in the Colombian Andes. Phil. Trans. R. Soc. B 2007, 362, 253-262. [CrossRef]

5. Cheng, Y.; Liu, H.; Dong, Z.; Duan, K.; Wang, H.; Han, Y. East Asian summer monsoon and topography co-determine the Holocene migration of forest-steppe ecotone in northern China. Glob. Planet. Chang. 2020, 187, 103135. [CrossRef]

6. Franco, A.M.; Hill, J.K.; Kitschke, C.; Collingham, Y.C.; Roy, D.B.; Fox, R.; Huntley, B.; Thomas, C.D. Impacts of climate warming and habitat loss on extinctions at species' low-latitude range boundaries. Glob. Chang. Biol. 2006, 12, 1545-1553. [CrossRef]

7. La Sorte, F.A.; Jetz, W. Projected range contractions of montane plant species diversity under global warming. Proc. R. Soc. B 2010, 277, 3401-3410.

8. Wu, J.; Zhang, S.; Jiang, Y. Botanical Geography; China Higher Education Press: Beijing, China, 1995.

9. Erdos, L.; Ambarlı, D.; Anenkhonov, O.A.; Bátori, Z.; Cserhalmi, D.; Kiss, M.; Naqinezhad, A.; Kröel-Dulay, G.; Liu, H.; Magnes, M.; et al. The edge of two worlds: A new review and synthesis on Eurasian forest-steppes. Appl. Veg. Sci. 2018, 21, 345-362. [CrossRef]

10. Dai, J.; Liu, H.; Xu, C.; Qi, Y.; Zhu, X.; Zhou, M.; Wu, Y.; Liu, B. Divergent hydraulic strategies explain the interspecific associations of co-occurring trees in forest-steppe ecotone. Forests 2020, 11, 942.

11. Cheng, Y.; Liu, H.; Wang, H.; Piao, S.; Yin, Y.; Ciais, P.; Gao, Y.; Wu, X.; Luo, Y.; Zhang, C.; et al. Contrasting effects of winter and summer climate on alpine timberline evolution in monsoon-dominated East Asia. Quat. Sci. Rev. 2017, 169, 278-287. [CrossRef]

12. Huang, X.Z.; Peng, W.; Rudaya, N.; Grimm, E.C.; Chen, X.; Cao, X.; Chen, F.; Zhang, J.; Pan, X.; Liu, S.; et al. Holocene vegetation and climate dynamics in the Altai Mountains and surrounding areas. Geophys. Res. Lett. 2018, 45, 6628-6636. [CrossRef]

13. Zhao, Y.; Tzedakis, P.C.; Li, Q.; Qin, F.; Cui, Q.; Liang, C.; Zhao, H.; Birks, H.J.B.; Liu, Y.; Zhang, Z.; et al. Evolution of vegetation and climate variability on the Tibetan Plateau over the past 1.74 million years. Sci. Adv. 2020, 6, eaay6193. [CrossRef] [PubMed]

14. Ji, Z.K.; Liu, H.Y. Shifting of vertical vegetation zones in Manas River drainage on northern slope of Tianshan Mountains since the Late Glacier. J. Palaeogeo. 2009, 11, 534-541. 
15. Gottfried, M.; Pauli, H.; Futschik, A.; Akhalkatsi, M.; Barančok, P.; Alonso, J.L.B.; Coldea, G.; Dick, J.; Erschbamer, B.; Calzado, M.R.F.; et al. Continent-wide response of mountain vegetation to climate change. Nat. Clim. Chang. 2012, 2, 111-115. [CrossRef]

16. Chen, F.H.; Yu, Z.; Yang, M.; Ito, E.; Wang, S.; Madsen, D.B.; Huang, X.; Zhao, Y.; Sato, T.; Birks, H.J.B.; et al. Holocene moisture evolution in arid central Asia and its out-of-phase relationship with Asian monsoon history. Quat. Sci. Rev. 2008, 27, 351-364. [CrossRef]

17. Long, H.; Shen, J.; Chen, J.; Tsukamoto, S.; Yang, L.; Cheng, H.; Frechen, M. Holocene moisture variations over the arid central Asia revealed by a comprehensive sand-dune record from the central Tian Shan, NW China. Quat. Sci. Rev. 2017, 174, 13-32. [CrossRef]

18. Zhang, D.; Chen, X.; Li, Y.; Wang, W.; Sun, A.; Yang, Y.; Ran, M.; Feng, Z. Response of vegetation to Holocene evolution of westerlies in the Asian Central Arid Zone. Quat. Sci. Rev. 2020, 229, 106138. [CrossRef]

19. Huang, X.Z.; Chen, C.Z.; Jia, W.N.; An, C.B.; Zhou, A.F.; Zhang, J.W.; Grimm, E.C.; Jin, M.; Xia, D.; Chen, F. Vegetation and climate history reconstructed from an alpine lake in central Tienshan Mountains since 8.5 ka BP. Palaeogeogr. Palaeoecol. 2015, 432, 36-48. [CrossRef]

20. Sun, X.; Du Naiqiu, W.C. Paleovegetation and paleoenvironment of Manasi Lake, Xinjiang, NW China during the last 14,000 years. Quat. Sci. 1994, 3, 239-248.

21. Li, J.; Gou, X.; Cook, E.R.; Chen, F. Tree-ring based drought reconstruction for the central Tien Shan area in northwest China. Geophys. Res. Lett. 2006, 33, L07715. [CrossRef]

22. Jiang, Q.F.; Ji, J.; Shen, J.; Matsumoto, R.; Tong, G.; Qian, P.; Yan, D.; Ren, X. Holocene vegetational and climatic variation in westerly-dominated areas of Central Asia inferred from the Sayram Lake in northern Xinjiang, China. Sci. China Earth Sci. 2013, 56, 339-353. [CrossRef]

23. Wang, W.; Feng, Z.; Ran, M.; Zhang, C. Holocene climate and vegetation changes inferred from pollen records of Lake Aibi, northern Xinjiang, China: A potential contribution to understanding of Holocene climate pattern in East-central Asia. Quat. Int. 2013, 311, 54-62. [CrossRef]

24. Chen, X.; Luo, G.; Xia, J.; Zhou, K.; Lou, S.; Ye, M. Ecological response to the climate change on the northern slope of the Tianshan Mountains in Xinjiang. Sci. China Earth Sci. 2005, 48, 765-777. [CrossRef]

25. Moore, P.D.; Webb, J.A.; Collison, M.E. Pollen Analysis; Blackwell Scientific Publications: Oxford, UK, 1991.

26. Cheng, Y.; Liu, H.; Wang, H.; Hao, Q. Differentiated climate-driven Holocene biome migration in western and eastern China as mediated by topography. Earth Sci. Rev. 2018, 182, 174-185. [CrossRef]

27. Gophen, M. Temperature Impact on the Shannon-Wiener Plant species diversity index (BDI) of Zooplankton in Lake Kinneret (Israel). Open J. Mod. Hydrol. 2018, 8, 39-49. [CrossRef]

28. Morris, E.K.; Caruso, T.; Buscot, F.; Fischer, M.; Hancock, C.; Maier, T.S.; Meiners, T.; Müller, C.; Obermaier, E.; Socher, S.A.; et al. Choosing and using diversity indices: Insights for ecological applications from the German biodiversity exploratories. Ecol. Evol. 2014, 18, 3514-3524. [CrossRef]

29. Marcott, S.A.; Shakun, J.D.; Clark, P.U.; Mix, A.C. A reconstruction of regional and global temperature for the past 11,300 years. Science 2013, 339, 1198-1201. [CrossRef]

30. Chen, F.; Wu, D.; Chen, J.; Zhou, A.; Yu, J.; Shen, J.; Wang, S.; Huang, X. Holocene moisture and East Asian summer monsoon evolution in the northeastern Tibetan Plateau recorded by Lake Qinghai and its environs: A review of conflicting proxies. Quat. Sci. Rev. 2016, 154, 111-129. [CrossRef]

31. Zhao, Y.; Yu, Z. Vegetation response to Holocene climate change in East Asian monsoon-margin region. Earth Sci. Rev. 2012, 113, 1-10. [CrossRef]

32. Hao, Q.; Liu, H.; Liu, X. Pollen-detected altitudinal migration of forests during the Holocene in the mountainous forest-steppe ecotone in northern China. Palaeogeogr. Palaeoecol. 2016, 446, 70-77. [CrossRef]

33. Liu, H.Y.; Yin, Y.; Zhu, J.; Zhao, F.; Wang, H. How did the forest respond to Holocene climate drying at the forest-steppe ecotone in northern China? Quatern. Int. 2010, 227, 46-52. [CrossRef]

34. Bush, M.B.; Silman, M.R.; Urrego, D.H. 48,000 years of climate and forest change in a plant species diversity hot spot. Science 2004, 303, 827-829. [CrossRef] [PubMed]

35. Sugita, S. Theory of quantitative reconstruction of vegetation II: All you need is LOVE. Holocene 2007, 17, $243-257$. [CrossRef] 
36. Sugita, S. Theory of quantitative reconstruction of vegetation I: Pollen from large sites REVEALS regional vegetation composition. Holocene 2007, 17, 229-241. [CrossRef]

37. Han, Y.; Liu, H.; Hao, Q.; Liu, X.; Guo, W.; Shangguan, H. More reliable pollen productivity estimates and relative source area of pollen in a forest-steppe ecotone with improved vegetation survey. Holocene 2017, 27, 1567-1577. [CrossRef]

38. Liu, H.Y. Quaternary Ecology and Global Change; China Science Press: Beijing, China, 2002.

Publisher's Note: MDPI stays neutral with regard to jurisdictional claims in published maps and institutional affiliations.

(C) 2020 by the authors. Licensee MDPI, Basel, Switzerland. This article is an open access article distributed under the terms and conditions of the Creative Commons Attribution (CC BY) license (http://creativecommons.org/licenses/by/4.0/). 